\title{
A HIGHLY SELECTIVE AND SENSITIVE ANALYTICAL TECHNIQUE FOR THE DETERMINATION OF ISOMALTULOSE IN PRESENCE OF ITS PROCESS RELATED IMPURITIES BY CAPILLARY ELECTROPHORESIS
}

\author{
Sri Rama Krishna Surapureddi ${ }^{1,2}$, Kunta Ravindhranath ${ }^{1, *}$, Krishnna \\ Darnasi $^{2}$ and Suhashini Ramen ${ }^{2}$ \\ ${ }^{1}$ Department of Chemistry, Koneru Lakshmaiah Education Foundation, Green Fields, \\ Vaddeswaram, Guntur District, Andhra Pradesh, India - 522502 \\ ${ }^{2}$ Vimta Labs Ltd, Genome Valley, Hyderabad, Telangana, India-500085. \\ *E-mail: ravindhranath.kunta@gmail.com
}

\begin{abstract}
Isomaltulose is a rare disaccharide and has drawn the attention of the pharmaceutical and food industry due to its medical applications. In the present investigation, a simple first of its kind capillary electrophoresis (CE) method is developed and validated for the identification and quantification of isomaltulose and its process impurities (trehalulose, sucrose, d-glucose and d-fructose). The analysis is performed at $\mathrm{pH}$ : 12.6 using an electrolyte buffer containing $36 \mathrm{mM}$ of $\mathrm{Na}_{2} \mathrm{HPO}_{4}$ and $130 \mathrm{mM} \mathrm{NaOH}$. The calibration curves are plotted over a concentration range from $0.25 \mathrm{mM}$ to $3.0 \mathrm{mM}$ with the regression of 0.99 and with detection limits of $0.15 \mathrm{mM}, 0.14 \mathrm{mM}, 0.13 \mathrm{mM}$, $0.10 \mathrm{mM}$ and $0.23 \mathrm{mM}$ for isomaltulose, trehalulose, sucrose, d-glucose and d-fructose respectively. Concerning the internal standard, d-trehalose, the relative migration time is $1.32 \mathrm{~min}$ for isomaltulose. Better resolution is achieved under optimum conditions of $18^{\circ} \mathrm{C}$ temperature, $16 \mathrm{kV}$ capillary voltage and $\mathrm{pH}$ of 12.6 . The method is found to be specific for the intended purpose and can be used as an orthogonal approach to the current existing United States Pharmacopoeia (USP) High-performance liquid chromatography (HPLC) monograph method.
\end{abstract}

Keywords: Isomaltulose /Palatinose, Capillary Electrophoresis Analysis, Disaccharide.

(C) RASĀYAN. All rights reserved

\section{INTRODUCTION}

Carbohydrates are the key macronutrients and constitute nearly half of the calories in a balanced diet and among which, sugars are the major constituents ${ }^{1}$. Various food and health safety agencies identified the role of the added sugars and their impact on health issues like type 2 diabetes (T2D), obesity and developing dental caries. The World Health Organization (WHO) and the Dietary Guidelines Advisory Committee (DGAC) have set up an upper limit for free sugars as lesser than 10\% of the total energy intake. However, in recent times, the Scientific Advisory Committee on Nutrition (SACN) has recommended to further reduce the free sugars to less than $5 \%$ of the total energy intake ${ }^{2}$. Many studies have confirmed an alliance between the intake of sugars and dental caries ${ }^{3}$. Rare disaccharides are widely used to avoid the ill effects of traditional sugars as they have low calories in comparison with regular sugars. These are non-carcinogenic and are found in small amounts in nature. Remarkably, many of them have great economic value in nutrition, cosmetics and pharmaceutical industries ${ }^{4}$. They are also considered as potential raw materials in food processing and beverage production, and also in research areas. At present, the production of a rare disaccharide is through synthetic (chemical) routes and these methods are not economical due to expensive raw materials. In contrast, the productions of rare disaccharide through enzymatic methods are cost-effective. One of the rare disaccharides is isomaltulose, which is also called as palatinose. In 2008, the United States Food and Drug Administration (US FDA) approved the isomaltulose and registered under Generally Recognized as Safe (GRAS). When isomaltulose is consumed, it is hydrolyzed and absorbed in the form of glucose and fructose in the small

Rasayan J. Chem., 13(2), 836-844(2020)

http://dx.doi.org/10.31788/RJC.2020.1325686

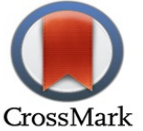


RASĀYAN J. Chem.

Vol. 13 | No. 2 |836 - 844| April - June | 2020

intestine. There are no side effects observed on human health when referred to the biological data, toxicological and metabolic studies of isomaltulose. This rare disaccharide is in use as a substitute for sugar in food since 1985 in Japan, 2005 in European Union (EU), 2006 in the United States (US), 2007 in Australia and New Zealand ${ }^{5}$. Isomaltulose and trehalulose are two structural isomers of sucrose, present in small quantities in honey and sugar cane ${ }^{6}$. The non-carcinogenic properties of isomaltulose and trehalulose have made them a frontline alternative to sucrose as a sugar substitute in food. As compared to sucrose, isomaltulose has a negligible impact on the glucose concentration in the blood, which is beneficial for both diabetic and non-diabetic people. The glycemic index (GI) of isomaltulose is 32 whereas that of sucrose is $72^{5}$. As these rare disaccharides are present in very fewer amounts, there is a need to produce them. At present, the production of rare disaccharides is through synthetic (chemical) routes and these methods are not economical due to expensive raw materials. In contrast, the productions of rare disaccharides through enzymatic methods are cost-effective. Various microorganisms can produce rare disaccharides. Microorganisms like Serratia plymuthica, Erwinia rhapontici, Pseudomonas mesoacidophila MX-45 10, Agrobacterium radiobacter MX-232 and Klebsiella planticola CCRC 19112. A. radiobacter MX-232 and Pseudomonas mesoacidophila MX-45 produce more trehalulose than Isomaltulose..$^{8-13}$ Similarly, Isomaltulose is produced more by $S$. plymuthica NCIB 8285, E. rhapontici NCPPB 1579, K. planticola CCRC 19112 and Protaminobacter rubrum. ${ }^{8,912,14}$ Current advances in molecular biology paved ways to use recombinant enzymes that can be used for the production of isomaltulose using sucrose as a substrate.

Analysis of carbohydrates is perplexing due to its complex structure, heterogeneity, lack of chromophore and highly polar nature. Existing analytical methods like HPLC, gas chromatography (GC), etc. have been used to quantify sugars after pre-column derivatization ${ }^{15-17}$. Though these methods offer high resolution and are highly sensitive, they are time-consuming and the reagents are not so economical. Additionally, derivatization based analyses of sugars by HPLC or GC have certain limitations such as excess consumption of reagent ${ }^{18}$. On the other hand, High-Performance Anion Exchange Chromatography coupled with Pulsed Amperometric Detection (HPAEC-PAD) is found to be a useful technique for sugar analysis. However, according to Oshima $\mathrm{H}$ et al 2006, HPAEC-PAD analysis is not sensitive enough due to the partial conversion of $\mathrm{d}$-fructose to d-psicose. ${ }^{19}$ Despite the availability of different analytical methods for identification and quantification of rare disaccharides, an alternative approach, using capillary electrophoresis with many merits is currently being evaluated. It has many advantages like less buffer consumption and high throughput. Additionally, sample dilutions are simple and minimal sample quantity and reagents are consumed during the analysis. More importantly, good separation with a high degree of resolution is achieved in a wide range of $\mathrm{pH}$, which is attributed to the repulsions of charged species or ions in an electric field. ${ }^{20}$

Recently capillary zone electrophoresis (CZE) methods are introduced to quantify the neutral sugars through indirect and direct UV detection methods with various background electrolytes (BGEs) ${ }^{21}$. Stella Rovio and co-workers validated the methods, where the saccharides can be analyzed using direct UV detection at $270 \mathrm{~nm}$ and high $\mathrm{pH}$ background. The indirect UV detection of CE has a drawback of sample recovery ${ }^{22}$. Recently, some studies described that the analysis through direct UV detection is based on the typical alkaline degradation of sugars conjugated with enol carbonyl group that produces UV absorption at $265 \pm 5 \mathrm{~nm}^{22-24}$. An attempt has been made earlier with capillary electrophoresis for the separation of process-related impurities of isomaltulose, in which trehalulose is co-migrated with d-fructose. ${ }^{25}$ The present investigation endeavors to develop a highly sensitive and selective analytical technique for identification and quantification of isomaltulose in presence of its process-related impurities, by capillary electrophoresis with a good and improved resolution between these rare disaccharides.

\section{EXPERIMENTAL}

\section{Chemicals}

D-glucose, d-fructose, sucrose, trehalulose, isomaltulose, d-trehalose, disodium hydrogen phosphate $\left(\mathrm{Na}_{2} \mathrm{HPO}_{4}\right.$ ) and sodium hydroxide $(\mathrm{NaOH})$ were procured from Sigma-Aldrich (India)/BOC Sciences (US). $\mathrm{pH}$ calibration buffers 1.68 and 12.00 were procured from Reagecon and other buffers of $\mathrm{pH} 4.00$, 7.00 and 9.20 were procured from Merck. Acids (Hydrochloric acid and Acetic acid) were also procured 


\section{RASĀYAN J. Chem. \\ Vol. 13 | No. 2 |836 - 844| April - June | 2020}

from Merck. HPLC grade water and analytical grade chemicals were used in the present analysis. $25 \mathrm{mM}$ concentration stock solutions of glucose, fructose, sucrose, isomaltulose and trehalulose were prepared. An effective length of $50.2 \mathrm{~cm}(60 \mathrm{~cm}$ actual length) fused-silica capillaries and capillary electrophoresis apparatus were purchased from Sciex, USA. Commercial samples were collected from the local market with three different suppliers.

\section{Background Electrolyte}

An alkaline running buffer (electrolyte) solution containing $36 \mathrm{mM} \mathrm{Na}_{2} \mathrm{HPO}_{4} \cdot 2 \mathrm{H}_{2} \mathrm{O}$ and $130 \mathrm{mM} \mathrm{NaOH}$ was prepared by mixing $1.0 \mathrm{M}$ sodium hydroxide $(\mathrm{NaOH})$ solution with $450 \mathrm{mM}$ stock solution of disodium hydrogen phosphate dihydrate. The $\mathrm{pH}$ of the electrolyte solution was measured with a Mettler Toledo (GMBH- model\#8603) $\mathrm{pH}$ meter. Before measuring the electrolyte $\mathrm{pH}$, the instrument was calibrated with standard buffers of $\mathrm{pH} 1.68( \pm 0.01), 4.00( \pm 0.01), 7.00( \pm 0.01), 9.20( \pm 0.01)$, and 12.00 $( \pm 0.01)$. The $\mathrm{pH}$ of the electrolyte solution was adjusted to $12.6( \pm 0.01)$ and ionic strength to $0.217 \mathrm{M}^{22}$. Standard stock solutions of $25 \mathrm{mM}$ of each sugar, glucose, fructose, sucrose, isomaltulose and trehalulose and working standard solutions in the concentration range of $0.25,0.5,1.0,2.0$ and $3.0 \mathrm{mM}$ were prepared with appropriate dilutions using water (HPLC grade). The internal standard: trehalose $(1.0 \mathrm{mM})$ was employed to spike the working standards and commercial samples. The standard stock solutions were stored at 4 to $8{ }^{\circ} \mathrm{C}$. As suggested by Stojakovic et al 2013, freshly prepared electrolyte solution was used to reduce the carbon dioxide influence on background electrolyte for better reproducibility ${ }^{26}$.

\section{Instrumentation and Electrophoretic Procedures}

All experiments were carried out employing a computer loaded with a 32 karat software-controlled capillary electrophoresis system (CE PA800 plus, Beckman Coulter Inc.). An effective length of $50.2 \mathrm{~cm}$ (60 $\mathrm{cm}$ actual length) fused-silica capillary with a $50 \mu \mathrm{m}$ inner diameter was employed for the investigation. A background electrolyte (BGE) consists of $36 \mathrm{mM} \mathrm{Na}_{2} \mathrm{HPO}_{4}$ and $130 \mathrm{mM} \mathrm{NaOH}$ was adjusted to a $12.6 \mathrm{pH}$ with $1.0 \mathrm{M} \mathrm{HCl} .10 \%(\mathrm{v} / \mathrm{v})$ acetic acid was prepared in water. All sugars were effectively separated using a BGE and at a steady voltage of $16 \mathrm{kV}$ and a cartridge temperature of $18{ }^{\circ} \mathrm{C}$.

New capillaries were pretreated by flushing with $1 \mathrm{M} \mathrm{NaOH}$ for 5 min before use, then treated with background electrolyte for 5 mins, again flushed with $1 \mathrm{M} \mathrm{NaOH}$ for 5 min and finally flushed with water for $5 \mathrm{~min}$. Capillaries were preconditioned with background electrolyte for $2 \mathrm{~min}$ before injection.

As suggested by Rovio et al 2007, with the pressure of 0.5 psi, the samples were injected for 5 seconds (approximately $5.9 \mathrm{~nL}$ ) using hydrodynamic injection mode into a capillary at $18{ }^{\circ} \mathrm{C}$ temperature followed by background electrolyte inoculation with 0.5 psi for 5 seconds ${ }^{24,27}$. The separation was carried out at $16 \mathrm{kV}$ for 25 minutes with background electrolyte. The photodiode array (PDA) detector set at 270 $\mathrm{nm}$ was used for detection.

After each sample run, the capillary was washed by flushing with $10 \% \mathrm{CH}_{3} \mathrm{COOH}$ for 4 minutes, water for 3 minutes and background electrolyte for 3 minutes and then the separation was carried out with background electrolyte for 1 minute. Rinsing was performed at a constant pressure of 20 psi.

\section{Optimization of the Separation Technique}

\section{RESULTS AND DISCUSSION}

The effect of different voltages and temperatures was investigated as part of optimization. It was observed that alkaline BGE buffer comprising of $36 \mathrm{mM} \mathrm{Na}_{2} \mathrm{HPO}_{4}$ and $130 \mathrm{mM} \mathrm{NaOH}$ at $\mathrm{pH} 12.6$ was effective and a good separation was achieved when the voltage across the capillary was increased linearly from 0 to $16 \mathrm{kV}$ over two minutes and later maintained at a constant voltage of $16 \mathrm{kV}$ with a capillary temperature of $18{ }^{\circ} \mathrm{C}$. Obtained results are presented in Figs. -1 and 2. Figure-1 is the 3D spectrum of all the sugars, while Fig.-2 is a two-dimensional electropherogram of a mixture of mono and disaccharides.

\section{Optimization of Voltage}

The voltage applied across the $\mathrm{CE}$ also has a profound effect on the peaks resolutions and also on the migration times. Generally, voltage is inversely proportional to the migration time. Hence, the optimum voltage needed for good resolution with less migration time is a critical parameter that has to be assessed. 
RASĀYAN J. Chem.

Vol. 13 | No. 2 |836 - 844| April - June | 2020

In this investigation, the influence of voltage on the separation of sugar mixtures was assessed by performing experiments with varying voltages from 15.0 to $18.0 \mathrm{kV}$ across the capillaries using the same electrolyte solution $\left(130 \mathrm{mM} \mathrm{NaOH}\right.$ and $\left.36 \mathrm{mM} \mathrm{Na}_{2} \mathrm{HPO}_{4}\right)$ and keeping the $\mathrm{pH}$ constant at 12.6 with cartridge temperature $24^{\circ} \mathrm{C}$. The findings are presented in Fig.-3.

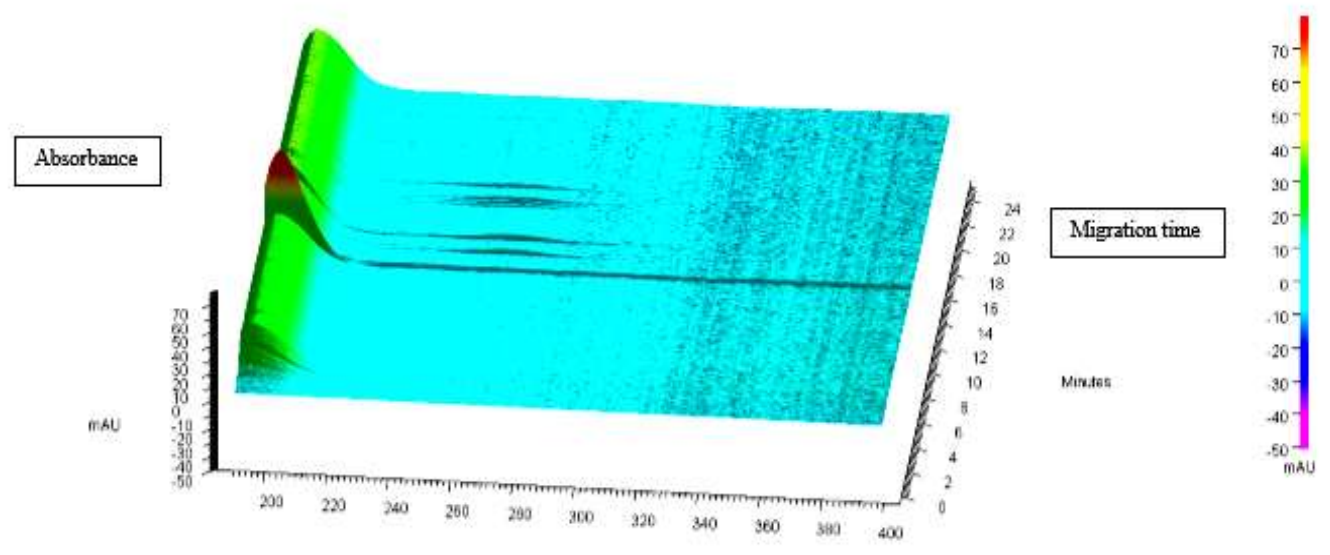

\section{Wavelength}

Fig.-1: 3D Spectrum for All Separated Sugars at the Optimum Conditions of Resolution

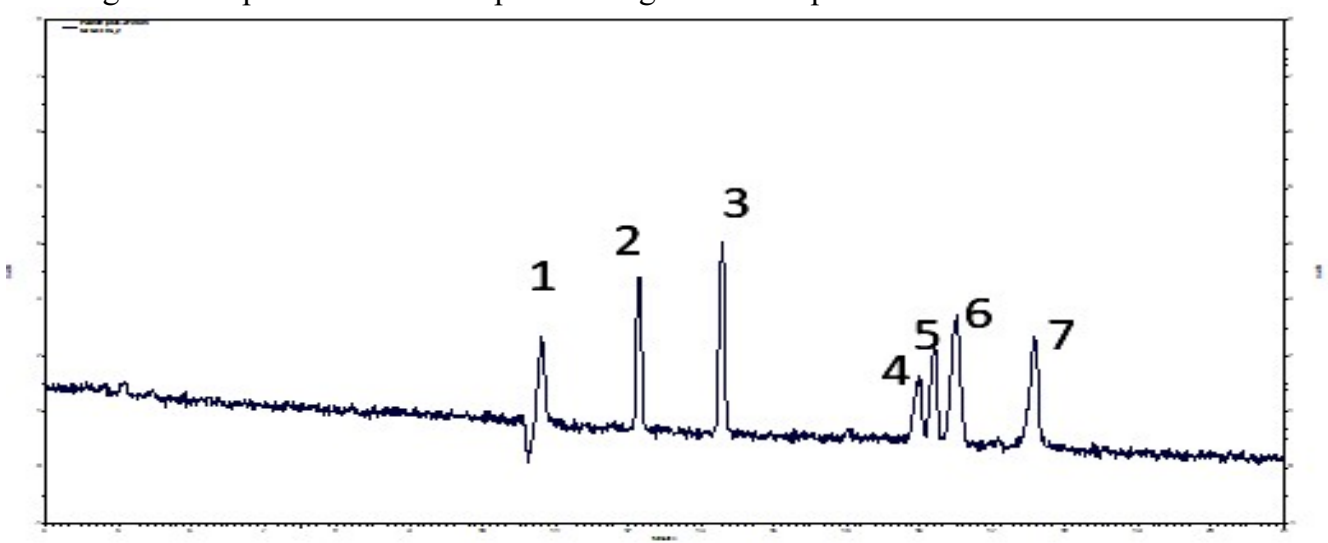

Fig.-2: Electropherogram of A Mixture of Monosaccharides ( $2 \mathrm{mM}$ of each

Sugar). Separation of Six Sugars in Electrolyte Solution of $36 \mathrm{mM} \mathrm{Na}_{2} \mathrm{HPO}_{4}$ and $130 \mathrm{mM} \mathrm{NaOH}$; $\mathrm{pH}$ 12.6;

Separation Voltage $16 \mathrm{kV}$ and $19^{\circ} \mathrm{C}$ Cartridge Temperature ; Peak ids: 1: EOF, 2: d-Trehalose, 3: sucrose, 4 : isomaltulose, 5: trehalulose, 6: d-Glucose and 7: d-fructose

From the obtained data it is evident that with an increase in voltage, the migration time of sugars is reducing, which is as expected. At a voltage of $15 \mathrm{kV}$, except trehalulose and d-glucose, all the other sugars were well resolved. But with the increase in voltage to $16 \mathrm{kV}$, the resolution between trehalulose and d-glucose is progressive and a valley between the peaks of trehalulose and d-glucose is getting deepened. With a further increase in the voltage to $17 \mathrm{kV}$ and $18 \mathrm{kV}$, the peaks of trehalulose and dglucose were merged and co-migrated. So from the experiments that were performed with different voltages, it can be inferred that $16 \mathrm{kV}$ is optimum, where better resolution is observed. This voltage is adopted to further investigate the effect of temperature on the resolution.

\section{Effect of Cartridge Temperature}

To improve the resolution between trehalulose and d-glucose peaks, experiments were performed at 16 , 18,20 and $22{ }^{\circ} \mathrm{C}\left( \pm 1{ }^{\circ} \mathrm{C}\right)$ by maintaining $\mathrm{pH}$ of the background electrolyte at 12.6 and the optimized voltage of $16 \mathrm{kV}$. The results are presented in Fig.-4. From the obtained data it can be inferred that with a 
RASĀYAN J. Chem.

Vol. 13 | No. 2 |836 - 844| April - June | 2020

decrease in temperature from $22^{\circ} \mathrm{C}$ to $18^{0} \mathrm{C}$, the resolution between trehalulose and d-glucose is progressively increased and at $18^{\circ} \mathrm{C}$, the resolution of all sugars is good. But when the temperature is further decreased to $16^{\circ} \mathrm{C}$, isomaltulose and trehalulose peaks were getting merged. Hence, $18{ }^{\circ} \mathrm{C}$ is considered as optimum temperature, where a considerable resolution was achieved, which is greater than $1.2($ Table-1)

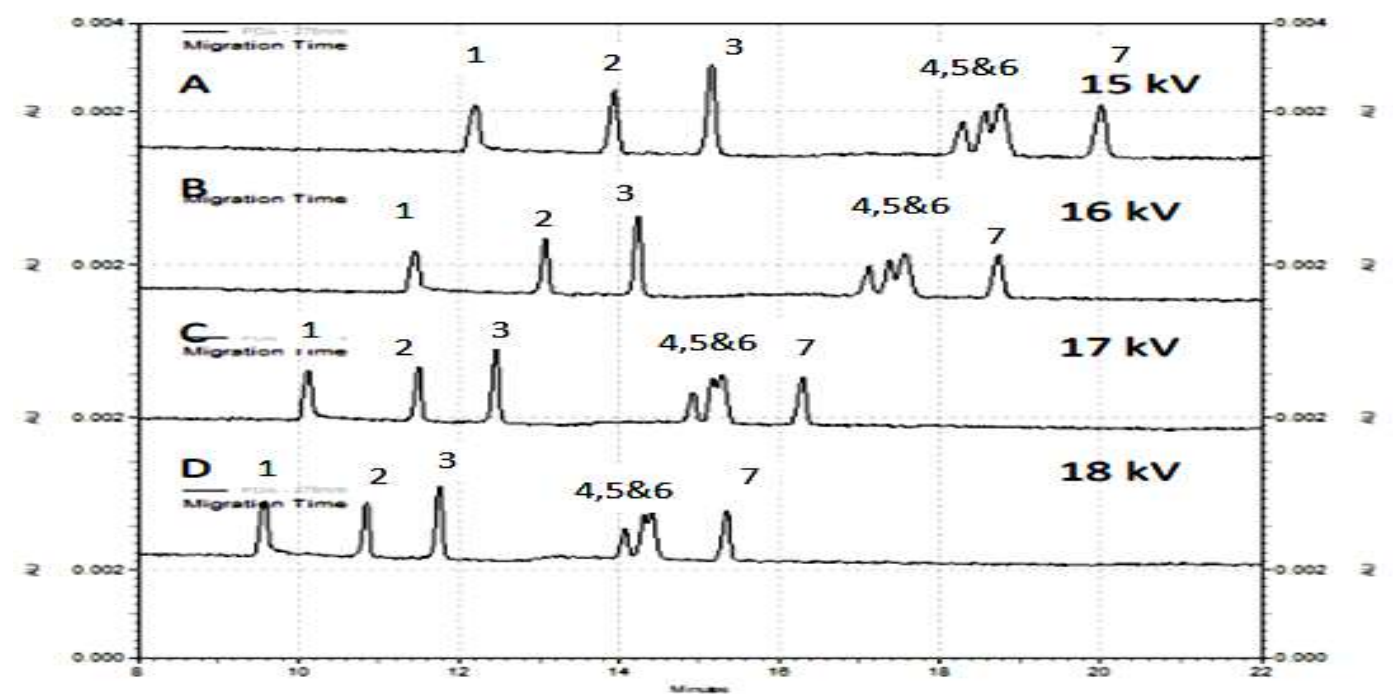

Fig.-3: Separation of Six Sugar Mixtures in An Electrolyte Solution of $\mathrm{pH} 12.6$ and $24^{\circ} \mathrm{C}$ Cartridge Temperature at Different Separation Voltages. (A) 15kV, (B) 16kV, (C) 17kV, (D) 18kV. Peak ids: 1: EOF, 2: d-Trehalose, 3: sucrose, 4: isomaltulose, 5: trehalulose, 6: d-Glucose and 7: d-Fructose.

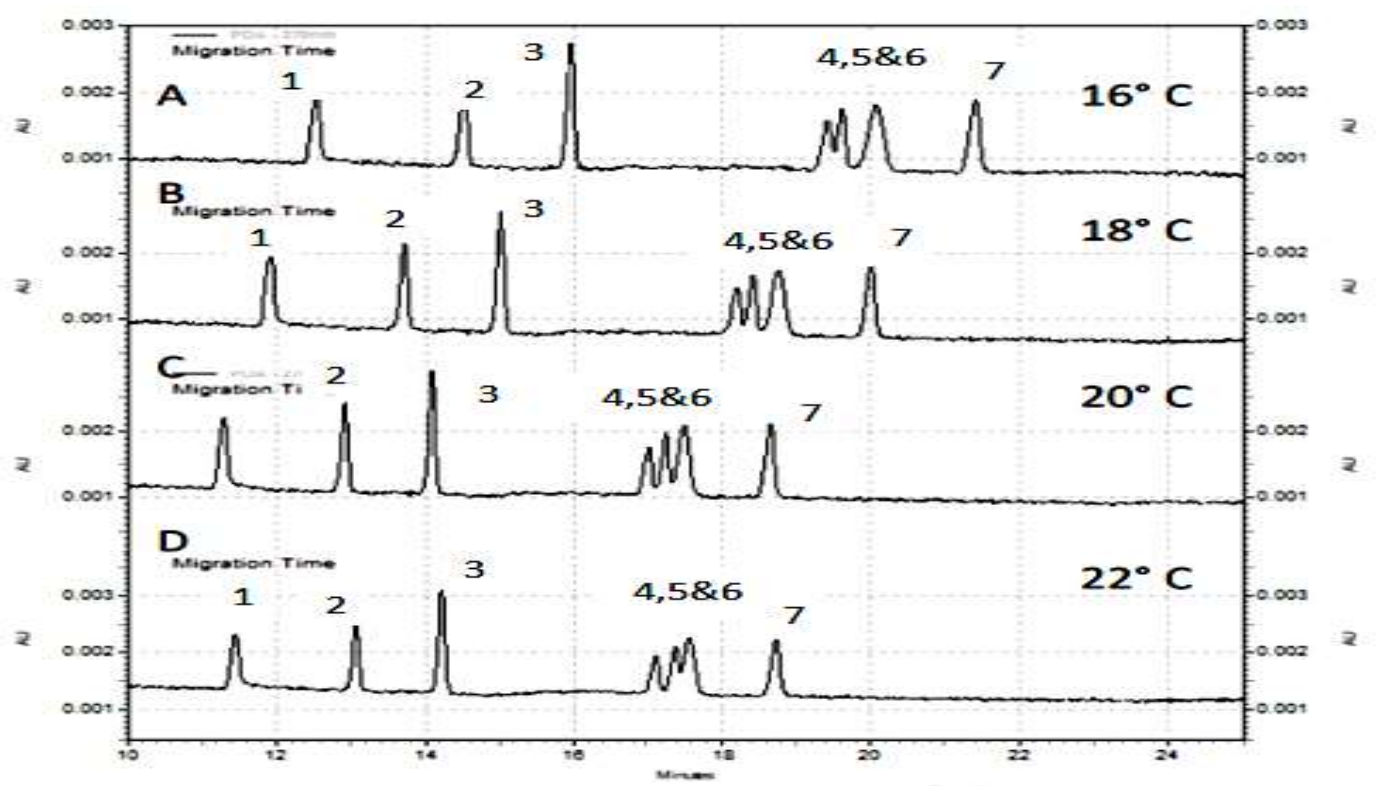

Fig.-4: Separation of Six Sugar Mixtures in An Electrolyte Solution of pH 12.6 and Separation Voltage at 16kV with Different Cartridge Temperatures. (A) $16^{\circ} \mathrm{C}$, (B) $18^{\circ} \mathrm{C},(\mathrm{C}) 20^{\circ} \mathrm{C}$, (D) $22^{\circ} \mathrm{C}$. Peak ids: 1 : EOF, 2: d-Trehalose, 3: sucrose, 4: isomaltulose, 5: trehalulose, 6: d-Glucose and 7: d-Fructose.

Thus, the optimum separation conditions for the satisfactory separation of the sugars taken for the current study were found to be: applied voltage: $16 \mathrm{kV}$, injection pressure 0.5 psi for 5 seconds, capillary: 50/66 cms, separation temperature $18{ }^{\circ} \mathrm{C}$, electrolyte solution: $130 \mathrm{mM} \mathrm{NaOH} 36 \mathrm{mM}$ and $\mathrm{Na}_{2} \mathrm{HPO}_{4} \cdot 2 \mathrm{H}_{2} \mathrm{O}$ and $\mathrm{pH}: 12.6$. 
RASĀYAN J. Chem.

Vol. 13 | No. 2 |836 - 844| April - June | 2020

\section{Validation}

To further strengthen the suitability of the method developed for the intended purpose, the method was validated with all the critical parameters that include linearity, reproducibility (intraday and interday), the limit of detection and specificity. The BGE solution consists of $36 \mathrm{mM}$ of $\mathrm{Na}_{2} \mathrm{HPO}_{4}$ and $130 \mathrm{mM} \mathrm{NaOH}$ with optimized conditions, viz. $\mathrm{pH} 12.6$, cartridge temperature $18^{\circ} \mathrm{C}$ and voltage of $16 \mathrm{kV}$ were used for all the validation experiments. By analyzing all the sugars, specificity was determined as individual runs and independently post spiking of all sugars with the internal standard (a known quantity). Isomaltulose has shown a migration time of 15.99 minutes with a resolution (USP) of 16.19 concerning substrate (sucrose). Further, the resolution between all other sugars and Isomaltulose is found to be satisfactory. The results are presented in Table-1.

Table-1: Migration Time, Relative Migration Time, Resolution and Asymmetry of Sugars

\begin{tabular}{l|c|c|c|c}
\hline $\begin{array}{c}\text { Name of the } \\
\text { Sugars }\end{array}$ & $\begin{array}{c}\text { Migration } \\
\text { Time(min) }\end{array}$ & $\begin{array}{c}\text { Relative Migration } \\
\text { Time (min) }\end{array}$ & $\begin{array}{c}\text { Resolution } \\
\text { (USP) }\end{array}$ & $\begin{array}{c}\text { Asymmetry } \\
(10 \%)\end{array}$ \\
\hline d-Trehalose(IS) & 12.15 & 1.00 & 0.00 & 1.00 \\
\hline Sucrose & 13.29 & 1.09 & 8.62 & 0.95 \\
\hline Isomaltulose & 15.99 & 1.32 & 16.19 & 0.73 \\
\hline Trehalulose & 16.21 & 1.33 & 1.21 & 0.77 \\
\hline d-Glucose & 16.50 & 1.36 & 1.44 & 0.89 \\
\hline d-Fructose & 17.58 & 1.45 & 4.70 & 0.77 \\
\hline
\end{tabular}

\section{Linearity}

To find out the range of the method, a mixture of five sugars at know concentrations were prepared The concentration of each sugar in a mixture was adjusted to $0.25,0.5,1.0,2.0$ and $3.0 \mathrm{mM}$ and analyzed in the optimized experimental conditions. The coefficient of correlation was derived by plotting a graph between concentration versus response. The results of regression analyses are presented in Table- 2 and Fig.-5. The correlation coefficient for Isomaltulose was found to be 0.998 .

\section{Precision (Inter and Intraday)}

Method reproducibility was checked by performing precision using Trehalose as an internal standard and $2 \mathrm{mM}$ of each sugar mixture ( $\mathrm{n}=6) . \% \mathrm{RSD}$ was calculated for each sugar and is presented in Table- 2 . The limit of detection was calculated based on the slope method from calibration curves. LOD value for isomaltulose was observed as $0.15 \mathrm{mM}$. LOD values for all sugars are represented in Table- 2 .

Table-2: Calibration Ranges, Correlation Coefficient, Precision (Intra and Inter Day) and Limit of Detection.

\begin{tabular}{c|c|c|c|c|c}
\hline Name of the Sugars & $\begin{array}{c}\text { Linear } \\
\text { Range }(\mathrm{mM})\end{array}$ & $\begin{array}{c}\text { Correlation } \\
\text { Coefficient }\end{array}$ & $\begin{array}{c}\text { Limit of } \\
\text { Detection } \\
(\mathrm{mM})\end{array}$ & $\begin{array}{c}\text { Intraday } \\
(\% \mathrm{RSD})\end{array}$ & $\begin{array}{c}\text { Interday } \\
(\% \mathrm{RSD})\end{array}$ \\
\hline Sucrose & $0.25-3.0$ & 0.999 & 0.13 & 5.96 & 6.75 \\
\hline Isomaltulose & $0.25-3.0$ & 0.998 & 0.15 & 8.43 & 9.24 \\
\hline Trehalulose & $0.25-3.0$ & 0.999 & 0.14 & 6.46 & 7.35 \\
\hline Glucose & $0.25-3.0$ & 0.999 & 0.10 & 7.10 & 7.10 \\
\hline Fructose & $0.25-3.0$ & 0.997 & 0.23 & 5.40 & 6.64 \\
\hline
\end{tabular}

\section{Preparation and Assay of Standard and Commercial Samples Standard Samples}

To evaluate the optimized method, experiments were performed using Isomaltulose standard that was purchased from Sigma Aldrich. Five different preparations with a concentration of $2.0 \mathrm{mM}$ were prepared using HPLC grade water. Each standard solution was injected (spiked with internal standard) and analyzed. The average peak response ratios were calculated.

\section{Commercial Sample}

To further evaluate the applicability of this optimized method for samples from multiple sources purchased three samples of different makes through the amazon market with the trade name of palatinose 
RASĀYAN J. Chem.

Vol. 13 | No. 2 |836 - 844| April - June | 2020

from 3 different vendors. The sample solutions were prepared with a $2 \mathrm{mM}$ concentration of $\operatorname{sugar}(\mathrm{n}=3)$ and these samples were spiked with internal standard individually for the analysis. Each sample solution was injected in triplicates and calculated the average peak response ratio using the equations:

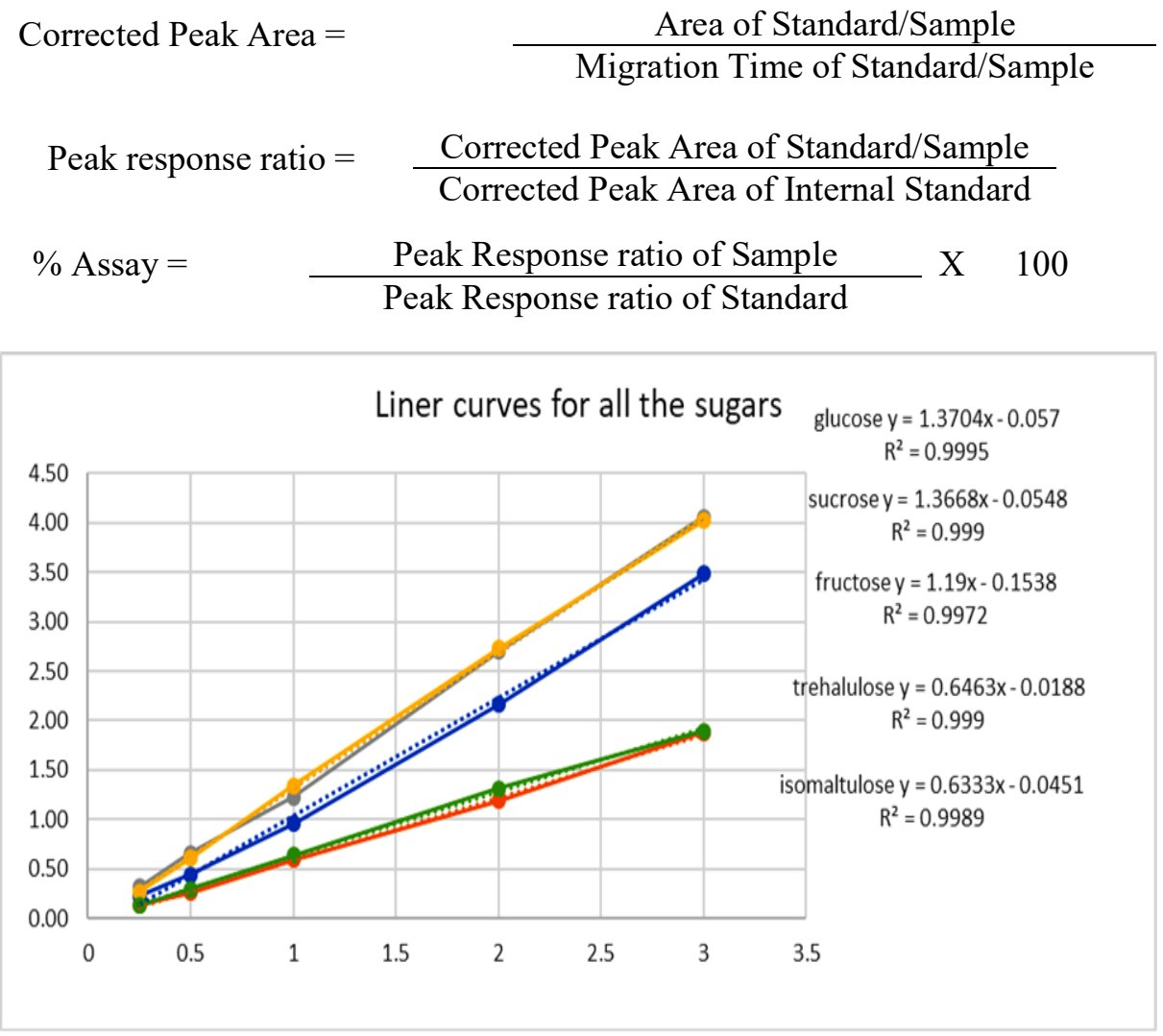

Fig.-5: Regression Analysis of Individual Sugars

The results obtained from commercial samples are presented in Table-3. It can be inferred from the Table that the observed content of isomaltulose in commercial samples concerning the standard is in agreement with the label assert and GRAS requirements of USFDA. Thus we claim that the present method is highly successful in determining the content of isomaltulose in sugar mixtures.

Table-3: \% Assay for Isomaltulose in Commercial Samples

\begin{tabular}{l|c|c}
\hline Name & $\begin{array}{c}\text { Average Peak Response Ratio } \\
\text { of Isomaltulose }\end{array}$ & $\%$ Assay \\
\hline \multicolumn{2}{c}{ Average Peak Response Ratio of Isomaltulose Standard = 0.989 } \\
\hline Isomaltulose Vendor -1 & 0.987 & 99.80 \\
\hline Isomaltulose Vendor -2 & 0.982 & 99.29 \\
\hline Isomaltulose Vendor -3 & 0.986 & 99.70 \\
\hline
\end{tabular}

\section{CONCLUSION}

The current study has shown the development of an efficient method for identification and quantification of isomaltulose along with other related impurities and successfully analyzed the commercially available isomaltulose as well. The method is further validated at $0.25 \mathrm{mM}$ to $3.0 \mathrm{mM}$ conc. series, for all the related sugars. Better resolution is achieved under optimum conditions of a temperature of $18{ }^{\circ} \mathrm{C}$, the capillary voltage of $16 \mathrm{kV}$ and a $\mathrm{pH}$ of 12.6. This method is applicable for the identification and quantification of enzymatically converted isomaltulose from sucrose. In addition to this, better resolution $(\mathrm{R}=16)$ can be obtained between the substrate (sucrose) and product (isomaltulose), even in the presence of other sugars like glucose, fructose and trehalulose. Commercially available isomaltulose samples were 
RASĀYAN J. Chem.

Vol. 13 | No. 2 |836 - 844| April - June | 2020

analyzed using the current method and observed a purity of $>99 \%$. These obtained findings are in agreement with the label claim and GRAS requirements of USFDA.

\section{ACKNOWLEDGMENT}

We thank KLEF, Vaddeswaram, Guntur District, Andhra Pradesh and the Management of Vimta Labs, Hyderabad for granting us the essential services to achieve this work. We thank Dr. U. Satyanarayana, Senior marketing manager, Waters India Pvt Ltd., Hyderabad, India, for the inputs while the work is in progress. The current investigation did not receive any specific grant from any funding agencies in the non-profit, commercial or public sectors.

\section{REFERENCES}

1. The National Academies Press, Washington, DC, 1358(2005), DOI:10.17226/10490.

2. L.M. Lamothe, K.A. Lê, R.A. Samra, O. Roger, H. Green, K. Macé, Critical Reviews in Food Science and Nutrition, 59(7), 1058(2017), DOI:10.1080/10408398.2017.1392287

3. R. Touger-Decker, C. van Loveren, The American Journal of Clinical Nutrition, 78, 881S(2003), DOI: $10.1093 / \mathrm{ajcn} / 78.4 .881 \mathrm{~S}$.

4. M. Bilal, H. Iqbal, H. Hu, W. Wang, X. Zhang, Critical Reviews in Food Science and Nutrition, 58(16), 2768(2018), DOI:10.1080/10408398.2017.1341385

5. C.C. Maresch, S.F. Petry, S. Theis, A. Bosy-Westphal, T. Linn, Nutrients 9 (2017), DOI: 10.3390/nu9040381

6. Z. Xu, S. Li, J. Li, Y. Li, X. Feng, R. Wang, H. Xu, J. Zhou, PLOS ONE 8, e74788, (2013), DOI: 10.1371 journal.pone. 0074788

7. T. Goda, N. Hosoya, Journal Of The Japanese Society For Food Science And Technology. 36, 169(1983).

8. S. Fujii, S. Kishihara, M. Komoto, J. Shimizu, Nippon Shokuhin Kogyo Gakkaishi 30, (1983), DOI: $10.3136 /$ nskkk1962.30.339

9. P.S. Cheetham, The Biochemical Journal 220, 213(1984), DOI:10.1042/bj2200213

10. Y. Nagai, T. Sugitani, K. Tsuyuki, Bioscience, Biotechnology, and Biochemistry 58, 1789(1994), DOI: $10.1271 / \mathrm{bbb} .58 .1789$

11. J. Nagai-Miyata, K. Tsuyuki, T. Sugitani, T. Ebashi, Y. Nakajima, Bioscience, biotechnology, and biochemistry, 57, 2049(1993), DOI:10.1271/bbb.57.2049

12. J.H. Huang, L. H. Hsu, Y. C. Su, Journal of Industrial Microbiology and Biotechnolog 21, 22(1998), DOI: $10.1038 /$ sj.jim.2900552

13. Y. Miyata, T. Sugitani, K. Tsuyuki, T. Ebashi, Y. Nakajima, Bioscience, Biotechnology, and Biochemistry 54, 1680(1992), DOI:10.1271/bbb.56.1680

14. R. Mattes, K. Klein, H. Schiwech, M. Kunz, M. Munir, Journal of Chromatography A, 1218, 1236(1998), DOI:10.1016/j.chroma.2011.01.002

15. K.R. Anumula, Analytical Biochemistry, 220, 275(1994), DOI:10.1006/abio.1994.1338

16. S. Honda, E. Akao, S. Suzuki, M. Okuda, K. Kakehi, J. Nakamura, Analytical Biochemistry 180, 351(1989), DOI:10.1016/0003-2697(89)90444-2

17. J. Suzuki, A. Kondo, I. Kato, S. Hase, T. Ikenaka, Clinical Chemistry, 38, 752(1992), DOI: $10.1093 /$ clinchem/38.5.752

18. Y.H. Lee, L. T. I, Journal of Chromatography.B, 681, 87(1996), DOI:10.1016/0378-4347(95)00503$\mathrm{X}$

19. Hisaka OSHIMA, I. K. a. K. I, Food Science and Technology Research 12, 137(2006), DOI: $10.3136 /$ fstr.12.137

20. I. Toro, J.F. Dulsat, J.L. Fabregas, J. Claramunt, Journal of Chromatography. A, 1043, 303(2004), DOI:10.1016/j.chroma.2004.05.091.

21. S.R.K. Surapureddi, R. Kunta, G.S. Sameer Kumar, S.R. Sappidi, S. Dadke, Food Chemistry 281, 36(2019), DOI:10.1016/j.foodchem.2018.12.081

22. S. Rovio, H. Simolin, K. Koljonen, H. Siren, Journal of Chromatography. A, 1185, 139(2008), DOI:10.1016/j.chroma.2008.01.031 
RASĀYAN J. Chem.

Vol. 13 | No. 2 |836-844| April - June | 2020

23. L. Zhao, A.M. Chanon, N. Chattopadhyay, I.E. Dami, J.J. Blakeslee, Frontiers in Plant Science, 7, 818, (2016), DOI: 10.3389/fpls.2016.00818

24. S. Rovio, J. Yli-Kauhaluoma, H. Siren, Electrophoresis, 28, 3129(2007), DOI: 10.1002/elps.200600783

25. L.W. Birch, Journal of Applied Microbiology. 97, 93(2004), DOI:10.1111/j.1365-2672.2004.02274.x

26. M. Stojkovic, T.D. Mai, P.C. Hauser, Analytica Chimica Acta, 787, 254(2013), DOI:10.1016/j.aca.2013.05.039

27. A.O. Alnajjar, A.M. Idris, Journal of Chromatographic Science, 52, 1104(2014), DOI: $10.1093 / \mathrm{chromsci} / \mathrm{bmt} 141$

[RJC-5686/2019] 